\title{
Does betting experience matter in sequential risk taking in horse race wagering?
}

\author{
Jani Saastamoinen* • Niko Suhonen \\ University of Eastern Finland, Finland
}

Received: 27 June 2018

Revised: 5 November 2018

Accepted: 5 November 2018

\begin{abstract}
This paper examines how betting experience is associated with horse race bettors' sequential risk taking. We use an individual-level data set of 5,217 individual bettors with 167,816 bettingrelated transactions. Our analyses suggest that inexperienced bettors take on more risk than experienced bettors do after they experience gains. We also find some indication that experienced bettors become more risk averse than inexperienced ones after incurring losses.
\end{abstract}

Keywords: experience; horse race betting; prospect theory; sequential risky decisions JEL Classification Codes: D91, G41

\section{Introduction}

This paper asks, "Does betting experience matter in sequential risk taking in horse race wagering?" Experimental and theoretical research into sequential risky decisions suggests that prior outcomes affect subsequent decisions. In a seminal experimental study, Thaler and Johnson (1990) extend the implications of Kahneman and Tversky's (1979) prospect theory to a dynamic setting. They find that relative to their prior choices, decision makers take on more risk after gains ('the house money effect'), exhibit risk aversion following losses but also prefer lotteries that provide an opportunity to break even ('the break-even effect'). More recently, Barberis and Xiong (2009) propose a model of dynamic risk taking under prospect theory, which predicts that relative to prior outcomes, a gain induces risk taking while a loss results in risk aversion. Recent empirical literature has reported evidence consistent with these findings (e.g. Liu et al. 2010, Smith 2009, Suhonen and Saastamoinen 2018). In particular, Suhonen and Saastamoinen (2018) investigate bettors risk-taking behavior in a horse race meeting. Their evidence is consistent with the house money effect, the break-even effect and risk aversion following losses which they refer to as "the playing safe effect".

\footnotetext{
*E-mail: jani.saastamoinen@uef.fi.

Citation: Saastamoinen, J., and Suhonen, N. (2018) Does betting experience matter in sequential risk taking in horse race wagering?, Economics and Business Letters, 7(4), 137-143.
} 
However, it is possible that market experience attenuates behavioral patterns (e.g. List 2004). Yet empirical research into how experience modifies risk-taking behavior is somewhat limited. Financial market research suggests that experience reduces the impact of behavioral biases (Feng and Seasholes 2005, Kaustia and Knüpfer 2008). In regard to risk taking, recent studies have found that inexperienced fund managers tend to assume riskier positions than their experienced peers (Greenwood and Nagel 2009, Chernenko et al. 2016). Thus, experience may affect how sensitive horse race bettors are to prior gains or losses in their subsequent risky taking.

This paper contributes to the literature by investigating differences between experienced and inexperienced bettors, and how experience is related to risk taking following gains and losses. We use online betting account data measured at the level of an individual bettor from a single race meeting. In this setting, bettors place their wagers in a closed time-frame, which resembles a laboratory-like environment involving consecutive risky decisions (e.g. Thaler and Ziemba 1988). This provides an opportunity to examine how a bettor's experience is related to his or her wagering decisions within a single event. The main finding of this paper is that inexperienced bettors increase their risk-taking in the domain of gains more than experienced ones do. However, they do not react to losses as strongly as experienced bettors who become more risk averse in the domain of losses.

This paper proceeds as follows. In section 2, we present the research design. Section 3 reports empirical results. Finally, Section 4 discusses the results.

\section{Methods}

In the empirical section, we follow the methodology applied by Suhonen and Saastamoinen (2018). They used the variance of bets ( arr $_{g, r}$ ) placed in each race by the bettor as a as a measure for a bet's riskiness in their statistical analyses, because it accounts for the wager's size and its odds. The variance of bets is a function of the amount wagered, the chosen odds and the probability of winning (see Suhonen and Saastamoinen (2018) for further details). It is intuitive that variance is increasing in bet size and the chosen odds. As an illustration, suppose that two bettors, A and B, both wager 10 euros in Win Bet. The odds of their chosen horses are 2 and 10, respectively. Then B's bet is riskier (has a higher variance) than A's wager. In a similar manner, if both players pick the same odds but wager with different bet sizes, higher stakes imply higher variance.

We test for whether the bettor's experience is associated with his or her risk taking following gain or losses. The formal regression model is

$$
\begin{aligned}
& \operatorname{Ln}\left(\text { Var }_{g, r}\right)=\alpha_{g}+\beta_{1} \text { CgainD }_{g, r}+\beta_{2} \text { CLoss }_{g, r}+\beta_{3} \text { CLoss }_{g, r}+\beta_{4} \text { CGain }_{g, r} \\
& +\sum_{j} \beta_{j} \text { Controls }_{g, r}+\varepsilon_{g, r}
\end{aligned}
$$

in which $g=1, \ldots, 5217$ and $r=1, \ldots, 10$ refer to a bettor and a race, respectively. The dependent variable is a logarithmic transformation $\operatorname{Ln}\left(\operatorname{Var}_{g, r}\right)$ of the total variance of bets of each bettor $g$ in each race $r$. The regression model is unbalanced because we only use the information on chosen bets. The analysis is carried out using a fixed-effects (FE) regression model because we are interested in within-group rather than between-group variations.

Since our measure for the bettor's experience remains fixed in a race meeting, it cannot be estimated using FE. For this reason, we follow the procedure applied in Camerer et al. (1997), who studied cab drivers' different wage elasticities for experienced and inexperienced cab drivers, and estimate two separate equations, one for the experienced bettors and another for the inexperienced bettors. After this, the impact of experience can be assessed by comparing the significance of the estimated coefficients between the two equations. The corresponding z-statistic is obtained from 


$$
z=\frac{b_{1}-b_{2}}{\sqrt{S E\left(b_{1}\right)^{2}+S E\left(b_{2}\right)^{2}}}
$$

where $b_{1}$ and $b_{2}$ are the unstandardized estimated coefficients from the estimated regression equations and $S E\left(\mathrm{~b}_{1}\right)^{2}$ and $S E\left(\mathrm{~b}_{2}\right)^{2}$ are their squared standard errors (see Clogg et al. 1995).

We examine how the bettor's experience is associate with the relationship between the bettor's current position with respect to the reference point and risk measurements. The focus variables include a dummy variable for the domain of gains (losses) GainD (LossD) which takes the value 1 for a race if before the race, the bettor's accumulated gains (losses) since his or her first bet are positive (negative). If GainD $>0$ (LossD $>0$ ), Cgain (Closs) accounts for the bettor's cumulative gain (loss) since his or her first bet. It indicates the bettor's distance from his or her reference point in the domain of gains (losses) prior to the next bet.

Although the data set does not include an exact measurement for experience, a proxy for experience could be constructed from bettors' identification numbers assigned to bettors in chronological order when the betting accounts were first registered. Hence, low identification numbers belong to bettors who have been involved with online horse race betting for a longer period of time. Subsequently, bettors could be divided in groups with respect to their experience. More specifically, we split bettors into two subsamples: experienced bettors and inexperienced bettors. After this, we estimate Eq. 1 for these two subsamples and assess the difference between the two groups using Eq. 2. Consequently, experience is correlated with the bettor's risk-taking decisions if estimated coefficients on the bettor's position with respect to the reference point are statistically different between the experienced and inexperienced bettors.

Several control variables are included in the regression model. First, unobservable race-specific effects are controlled for by assigning a dummy variable for each race. Second, since it is not necessary to place wagers on races in a consecutive order (e.g. one can place a bet on race 7 before wagering on race 5), open bets control for the potential influence exerted by the bettor's unrealized bets on his or her wagering decisions. Third, race rank which controls for a bettor's unobservable betting plans and changes in betting behavior during the race meeting. Finally, money transfers between a bettor's back account and betting account controls for unobservable changes in the bettor's mental betting account.

\section{Data}

We use online betting account data from a race meeting of ten consecutive horse races 1 . The races were held at Vermo racetrack, which is the main venue for harness horse racing in Finland, on August 1st, 2012. The sample includes 5,217 individual bettors with 167,816 betting-related transactions measured at the level of an individual bettor. The betting types available were Win Bet, Place and Quinella for all races, whereas Trifecta bets could be placed only in races 5 and 9. The betting account balance at the beginning of the day is the bettor's reference point against which his or her subsequent gains or losses, defined as cumulative returns on bets placed after each race, are reflected upon (Camerer 2000). Bettors may place bets until the last race is finished.

\section{Results}

The descriptive statistics are reported in Table 1 characterize bettors and their bets. The lefthand panel shows the descriptive statistics of the full sample. There are 5,217 individual bettors who bet on approximately four races on the race meeting in Vermo. The average bettor is a male

\footnotetext{
${ }^{1}$ The data set has been previously used by Suhonen and Saastamoinen (2018). They provide a more detailed description of the data source and the setting.
} 
Table 1. Descriptive statistics of bettors and bets placed.

\begin{tabular}{|c|c|c|c|c|c|c|c|c|}
\hline & \multicolumn{4}{|c|}{ Full sample } & \multicolumn{4}{|c|}{ Experienced } \\
\hline & Mean & S.D. & Min. & Max. & Mean & S.D. & Min. & Max. \\
\hline \multicolumn{9}{|l|}{ Demographic attributes } \\
\hline Age (years) & 50.7 & 12.9 & 18 & 87 & 51.4 & 11.9 & 22 & 85 \\
\hline Gender $($ female $=0$, male $=1)$ & 0.85 & 0.4 & 0 & 1 & 0.91 & 0.29 & 0 & 1 \\
\hline \multicolumn{9}{|l|}{ Day attributes } \\
\hline Number of races bet & 3.5 & 2.6 & 1 & 10 & 3.6 & 2.6 & 1 & 10 \\
\hline Number of bets placed & 30.7 & 54.8 & 1 & 1,106 & 32.9 & 56.9 & 1 & 813 \\
\hline Initial account before first bet & 62.6 & 176.4 & 1 & 5,237 & 70.3 & 188.5 & 0.5 & $4,250.4$ \\
\hline Daily bets $(€)$ & 36.5 & 71.7 & 1 & 1,700 & 42.7 & 84.7 & 0.5 & 1,700 \\
\hline Daily wins $(€)$ & 27.0 & 97.3 & 0 & 2,449 & 33.9 & 117.8 & 0 & 2,449 \\
\hline Daily return $(€)$ & -9.6 & 63.4 & -859 & 1,092 & -8.7 & 74.3 & -858.7 & 1091.8 \\
\hline \multicolumn{9}{|l|}{ Race attributes } \\
\hline Mean of bets per race $(€)$ & 10.9 & 20.7 & 1 & 850 & 12.2 & 25.1 & 0.5 & 850.0 \\
\hline Mean of wins per race $(€)$ & 6.8 & 31.4 & 0 & 1,225 & 8.5 & 39.4 & 0 & 1224.5 \\
\hline Mean of returns per race $(€)$ & -4.1 & 23.4 & -215 & 482 & -3.7 & 27.0 & -215.0 & 481.9 \\
\hline Number of bettors & & & & 5217 & & & & 2608 \\
\hline
\end{tabular}

Table 1 (cont). Decriptive statistics of bettors and bets placed.

\begin{tabular}{|c|c|c|c|c|c|}
\hline & \multicolumn{4}{|c|}{$\begin{array}{c}\text { Inexperienced } \\
\text {. }\end{array}$} & \multirow{2}{*}{$\begin{array}{c}\text { Experienced vs. Inexperienced } \\
\text { t-statistic }\end{array}$} \\
\hline & Mean & S.D. & Min. & Max. & \\
\hline \multicolumn{6}{|l|}{ Demographic attributes } \\
\hline Age (years) & 49.9 & 13.9 & 18 & 87 & $4.2 * * *$ \\
\hline Gender $($ female $=0$, male $=1)$ & 0.80 & 0.40 & 0 & 1 & $11.4 * * *$ \\
\hline \multicolumn{6}{|l|}{ Day attributes } \\
\hline Number of races bet & 3.4 & 2.6 & 1 & 10 & $2.8 * * *$ \\
\hline Number of bets placed & 28.4 & 52.5 & 1 & 1106 & $3.0 * * *$ \\
\hline Initial account before first bet & 54.9 & 163.1 & 0.5 & $5,236.8$ & $3.2 * * *$ \\
\hline Daily bets $(€)$ & 30.4 & 55.0 & 0.5 & 795.0 & $6.2 * * *$ \\
\hline Daily wins $(€)$ & 20.0 & 70.6 & 0 & 1449.7 & $5.2 * * *$ \\
\hline Daily return $(€)$ & -10.4 & 50.2 & -400 & 795 & 1.0 \\
\hline \multicolumn{6}{|l|}{ Race attributes } \\
\hline Mean of bets per race $(€)$ & 9.6 & 15.0 & 0.5 & 159 & $4.5 * * *$ \\
\hline Mean of wins per race $(\epsilon)$ & 5.2 & 20.4 & 0 & 332.1 & $3.8 * * *$ \\
\hline Mean of returns per race $(\epsilon)$ & -4.5 & 19.2 & -150 & 265 & 1.2 \\
\hline Number of bettors & & & & 2609 & \\
\hline
\end{tabular}

Note: *** significant at $1 \%$ level.

in his early fifties. Prior to the first bet, the average betting account balance is $€ 63$. The average of the total wagers placed in the day is approximately $€ 37$. The average net loss is $€ 10$ per day corresponding to roughly a quarter of the total amount of bets placed in a day. The average stake is $€ 11$ resulting in a net loss of $€ 4.1$ per a race.

The middle panel and the right-hand panel report the descriptive statistics relating to betting experience. Comparing the two groups indicates that on average, experienced as opposed to inexperienced bettors are older (51 vs. 49 years old) and more frequently male ( $91 \%$ vs. 80\%). Judged by the number of races wagered (32.9 vs. 28.4) on and the number of bets placed (3.6 vs. 3.4), they also bet more heavily. Judged by the monetary values, they have more money in their betting account ( $€ 70.3$ vs. $€ 54.9)$, spend more per day (€42.7 vs. $€ 30.4)$ and per race $(€ 12.2$ vs. €9.6), win more per day (€33.9 vs. €20.0) and per race (€8.5 vs. €5.2). All these differences are statistically significant. Interestingly, although experienced bettors earn higher average returns per day (-€8.7 vs. $-€ 10.4)$ and per race (-€3.7 vs. - €4.5) than inexperienced ones, these differences are not significant. However, even if the difference were statistically significant, it could result either from better knowledge regarding horses or from choices of different betting 
types as take-out rates differ across them.

Table 2 reports descriptive statistics of the variables used in the regression model for the full sample and for the groups of experienced and inexperience bettors separately. We also carry out t-tests (the right-hand panel of Table 2) to inspect if these variables are different between the two groups. The mean variance of bets is 1,751. Experienced bettors appear to make riskier wagers than inexperienced ones do $(2,076$ vs. 1,410$)$. The dummy variable GainD indicates that the average bettor is $14 \%$ of time in the domain of gains. Further, the statistics show that experienced bettors end up in the domain of gains more frequently $(0.15 \mathrm{vs.} 0.12)$. In contrast, the dummy variable Loss $D$ suggests that bettors spend a third of time in the loss domain. Cumulative gains are measured by the continuous variable Cgain. It indicates that the average bettor's gains are 6 euros. However, the average cumulative gains of experienced bettors are over two times the amount won by inexperienced bettors (8.1 euros vs. 3.9 euros). The continuous variable Closs records bettors' cumulative losses. The average loss is 6.7 euros. Relative to inexperienced bettors, however, experienced bettors incur more losses ( 7.7 euros vs. 5.8 euros). The control variables suggest that the average bettor has 4.8 euros in open bets when he or she gambles, he or she wagers in three races, and he or she transfers 6.6 euros from the bank account to the betting account while participating in wagering.

Table 2. Descriptive statistics of the variables used in the regression analyses.

\begin{tabular}{|c|c|c|c|c|c|c|c|c|}
\hline & \multicolumn{4}{|c|}{ Full sample } & \multicolumn{4}{|c|}{ Experienced } \\
\hline & Mean & S.D. & Min. & Max. & Mean & S.D. & Min. & Max. \\
\hline \multicolumn{9}{|l|}{ Dependent variable } \\
\hline $\operatorname{Ln}($ Var $)$ & 4.83 & 2.31 & -1.68 & 13.65 & 5.05 & 2.31 & -1.27 & 13.09 \\
\hline \multicolumn{9}{|l|}{ Independent variables } \\
\hline GainD $^{\#}$ & 0.14 & 0.35 & 0.00 & 1.00 & 0.15 & 0.36 & 0.00 & 1.00 \\
\hline $\operatorname{Loss} D^{\# \#}$ & 0.37 & 0.48 & 0.00 & 1.00 & 0.38 & 0.48 & 0.00 & 1.00 \\
\hline Cgain (in euros) & 6.04 & 39.64 & 0.00 & 1344.50 & 8.10 & 48.16 & 0.00 & 1344.50 \\
\hline Closs (in euros) & 6.74 & 22.22 & 0.00 & 907.50 & 7.68 & 26.08 & 0.00 & 907.50 \\
\hline \multicolumn{9}{|l|}{ Control variables } \\
\hline Open bets (in euros) & 4.83 & 16.80 & 0.00 & 406.00 & 4.94 & 17.23 & 0.00 & 308.00 \\
\hline Racerank & 3.20 & 2.21 & 1.00 & 10.00 & 3.23 & 2.21 & 1.00 & 10.00 \\
\hline Transfers (in euros) & 6.61 & 39.66 & -1600.00 & 1200.00 & 6.93 & 47.12 & -1600.00 & 900.00 \\
\hline Obs. & \multicolumn{4}{|c|}{10.9} & \multicolumn{4}{|c|}{20.7} \\
\hline
\end{tabular}

Table 2 (cont). Descriptive statistics of the variables used in the regression analyses.

\begin{tabular}{|c|c|c|c|c|c|}
\hline & \multicolumn{4}{|c|}{ Inexperienced } & \multirow{2}{*}{$\begin{array}{l}\text { Experienced vs. Inexperienced } \\
\text { t-statistic }\end{array}$} \\
\hline & Mean & S.D. & Min. & Max. & \\
\hline \multicolumn{6}{|l|}{ Dependent variable } \\
\hline $\operatorname{Ln}($ Var $)$ & 4.60 & 2.29 & -1.68 & 13.65 & $13.48 * * *$ \\
\hline \multicolumn{6}{|l|}{ Independent variables } \\
\hline GainD $^{\#}$ & 0.12 & 0.33 & 0.00 & 1.00 & $5.88 * * *$ \\
\hline $\operatorname{Loss} D^{\# \#}$ & 0.37 & 0.48 & 0.00 & 1.00 & 1.16 \\
\hline Cgain (in euros) & 3.87 & 27.88 & 0.00 & 830.00 & $7.23^{* * *}$ \\
\hline Closs (in euros) & 5.76 & 17.20 & 0.00 & 300.00 & $5.86 * * *$ \\
\hline \multicolumn{6}{|l|}{ Control variables } \\
\hline Open bets (in euros) & 4.72 & 16.33 & 0.00 & 406.00 & 0.89 \\
\hline Racerank & 3.18 & 2.22 & 1.00 & 10.00 & 1.39 \\
\hline Transfers (in euros) & 6.27 & 29.88 & -450.00 & 1200.00 & 1.13 \\
\hline Obs. & \multicolumn{4}{|c|}{8,944} & \\
\hline
\end{tabular}

Notes: *** significant at $1 \%$ level. ${ }^{\#}$ GainD equals one if a bettor is in the domain of gains and is zero otherwise.

\#\# Loss D equals one if a bettor is in the domain of losses and is zero otherwise. The descriptive statistics of the race dummy variables are not reported. 
Table 3. Results of risk-taking attitudes for experienced and inexperienced bettors in terms of variance.

\begin{tabular}{|c|c|c|}
\hline \multicolumn{3}{|c|}{ Method } \\
\hline Dependent Variable & & $\operatorname{Ln}($ Var) \\
\hline Independent Variable & Experienced & Inexperienced \\
\hline GainD & 0.0643 & $0.2667 * * *$ \\
\hline Std. Error & 0.0665 & 0.0727 \\
\hline z-value for difference & & $-2.05 * *$ \\
\hline LossD & $-0.1672 * * *$ & -0.0302 \\
\hline Std. Error & 0.0530 & 0.0547 \\
\hline $\mathrm{z}$-value for difference & & $1.77 *$ \\
\hline Cgain & 0.0005 & -0.0003 \\
\hline Std. Error & 0.0007 & 0.0009 \\
\hline z-value for difference & & 0.70 \\
\hline Closs & $-0.0032 * * *$ & $-0.0035 * *$ \\
\hline Std. Error & 0.0011 & 0.0014 \\
\hline z-value for difference & & 0.17 \\
\hline Constant & $4.7182 * * *$ & $4.3291 * * *$ \\
\hline Std. Error & 0.0589 & 0.0591 \\
\hline z-value for difference & & $4.66 * * *$ \\
\hline Controls & & Yes \\
\hline No. Bettors & 2608 & 2609 \\
\hline No. Observation & 9395 & 8944 \\
\hline Within $\mathrm{R}^{2}$ & 0.25 & 0.21 \\
\hline
\end{tabular}

Notes: *** significant at $1 \%$ level; ** significant at $5 \%$ level; * significant at $1 \%$ level. Controls include race dummies, racerank open bets and transfers. Robust standard errors are presented.

Estimates of risk-taking attitudes for experienced and inexperienced bettors in terms of variance are reported in Table 3. In respect of losses, the coefficient estimate on the dummy variable is negative and significant for the experienced bettors but insignificant for the inexperienced ones. The difference between the coefficient estimates is marginally significant at $10 \%$ level. Coefficient estimates on the size of accumulated loss are similar in magnitude (and significance) for both groups. Together, these results imply that both groups reduce risk-taking in the loss domain but inexperienced bettors make less of an adjustment at any given level of prior loss.

In the case of the domain of gains, inexperienced bettors appear to adjust their risk level upwards but the experienced bettors seem not to alter the degree of risk to which they expose themselves. This difference between the two groups is significant at 5\% level. Although the signs of the estimated coefficients on the accumulated gains are opposite between the two groups, they are not significant. Thus the results, whether with respect to prior losses or prior gains, indicate that experienced bettors tend to behave more cautiously. Overall, due to a rough proxy for experience, we believe that these findings should be treated with some caution.

\section{Discussion}

This paper addressed how betting experience is related to risk taking following gains or losses. Our findings suggest that experience matters. First, we find that the groups of experienced and inexperienced bettors differ from each other in terms of betting habits and demographic attributes. Second, inexperienced bettors increase their risk-taking in the domain of gains more than experienced ones do. Third, they do not react to losses as strongly as experienced bettors who become more risk averse in the domain of losses. An explanation for this could be that inexperienced bettors become overconfident in their gambling skills when they win which makes them less sensitive to losses. By contrast, experienced bettors may have learnt that a single gain or a 
few gains is not an indicator of a change in their skills and therefore does not affect their subsequent behavior. In this light, however, it is somewhat surprising that experienced bettors react so strongly to losses because one might assume an opposite effect taking place, namely that they would not be prone to change their behavior because of their prior learning. However, caution is warranted when interpreting these findings because the proxy for experience was crude and thus an imperfect measure of the betting market experience.

\section{Acknowledgment}

The authors wish to thank Juha Alho, Thomas Epper, David Forrest and the anonymous reviewer for their helpful comments. We express our gratitude to Fintoto Oy (Veikkaus Ltd) for providing the data, especially Pertti Koskenniemi and Reijo Anttila. We gratefully acknowledge the financial support from the Emil Aaltonen Foundation and the Finnish Foundation for Alcohol Studies.

\section{References}

Barberis, N., and Xiong, W. (2009) What Drives the Disposition Effect? An Analysis of a LongStanding Preference-Based Explanation, Journal of Finance, 64(2), 751-784.

Camerer, C. (2000) Prospect Theory in the Wild: Evidence from the Field. In Kahneman, D. and Tversky, A (Eds.) Choices, Values, and Frames. Cambridge University Press: Cambridge, 288-300.

Camerer, C., Babcock, L. Loewenstein, G., and Thaler, R. (1997) Labor Supply of New York City Cabdrivers: One Day at a Time, Quarterly Journal of Economics, 112, 407-441.

Chernenko, S., Hanson, S. G., and Sunderam, A. (2016) Who neglects risk? Investor experience and the credit boom, Journal of Financial Economics, 122, 248-269.

Clogg, C. C., Petkova, E., and Haritou, A. (1995) Statistical Methods for Comparing Regression Coefficients Between Models, American Journal of Sociology, 100(5), 1261-1293.

Feng, L., and Seasholes, M.S. (2005) Do Investor Sophistication and Trading Experience Eliminate Behavioral Biases in Financial Markets?, Review of Finance, 9(3), 305-351.

Greenwood, R., and Nagel, S. (2009) Inexperienced investors and bubbles, Journal of Financial Economics, 93(2), 239-258.

Kahneman, D., and Tversky, A. (1979) Prospect Theory: An Analysis of Decision under Risk, Econometrica, 47(2), 263 - 291.

Kaustia, M., and Knüpfer, S. (2008) Do Investors Overweight Personal Experience? Evidence from IPO Subscriptions, Journal of Finance, 63(6), 2679-2702.

List, J. (2004) Neoclassical Theory Versus Prospect Theory: Evidence from the Marketplace, Econometrica, 72(2), 615-625.

Liu, Y. J., Tsai, C. L., Wang, M. C., and Zhu N. (2010) Prior Consequences and Subsequent Risk Taking: New Field Evidence from the Taiwan Futures Exchange, Management Science, 56(4), 606-620.

Smith, G., Levere, M., and Kurtzman, R. (2009) Poker Player Behavior After Big Wins and Big Losses, Management Science, 55(9), 1547-1555.

Suhonen, N., and Saastamoinen, J. (2018) How Do Prior Gains and Losses Affect Subsequent Risk Taking? New Evidence from Individual-Level Horse Race Bets, Management Science, 64(6), 2797-2808.

Thaler, R. H., and Johnson, E. J. (1990) Gambling with the House Money and Trying to Break Even: The Effects of Prior Outcomes on Risky Choice, Management Science, 36(6), 643660.

Thaler, R. H., and Ziemba, W. T. (1988) Anomalies: Parimutuel Betting Markets: Racetracks and Lotteries, Journal of Economic Perspectives, 2(2), 161-174. 